\title{
Testing a dual-source heat pump
}

\author{
M. Cannistraro ${ }^{1 *}$, E. Mainardi ${ }^{2}$, M. Bottarelli ${ }^{1}$ \\ ${ }^{1}$ Department of Architecture, University of Ferrara, Via Quartieri 8, Ferrara 44121, Italy \\ ${ }^{2}$ Department of Engineering, University of Ferrara, Via Saragat 1, Ferrara 44121, Italy
}

Corresponding Author Email: mauro.cannistraro@unife.it

https://doi.org/10.18280/mmep.050311

Received: 26 February 2018

Accepted: 11 June 2018

\section{Keywords:}

dual-source heat pump, horizontal ground heat exchangers, flat-panel

\begin{abstract}
Air-source and ground coupled heat pumps are depicted as energy efficient systems. Nevertheless, the ground coupling incurs in expensive extra-costs owing to the ground heat exchangers (GHEs), whereas the air exploitation suffers lower temperatures and frosting conditions. Coupling both solutions in a dual-source heat pump system (DSHP) can mitigate the former drawbacks. The present paper analyses the performance of a DSHP experimental prototype, installed as the air-conditioning system of a testing room at the University of Ferrara, Italy. The prototype is composed by a common air-to-air heat pump and a geothermal closed loop. The refrigerant circuit of the heat pump has been modified to couple on demand the closed loop by means of a plate heat exchanger. As GHE type, the Flat-Panel solution has been chosen due to its higher performance respect to all other horizontal and shallow exchangers. The switching between air and ground is automatized by mean of a control unit, according to the best thermal conditions, and the closed loop is also partializable to evaluate the length impact on the switching rules. The DSHP flexibility has allowed better performance than the original air-to-air heat pump, especially under hard weather conditions, and therefore an overall energy saving.
\end{abstract}

\section{INTRODUCTION}

European Community encourages cooperation and coordination among European companies and researchers by promoting development of low-carbon energy technologies and policies to increase the use of renewable resource within 2020 [1]. Reversible air-source heat pumps (ASHPs) and ground coupled heat pumps (GCHPs) are regarded as viable and efficient technology for space cooling and heating of residential and commercial buildings.

The climate conditions in northern and central Europe, in which most of this marketplace expansion occurs, show that the energy performances are affected by frosting phenomenon and lowering yield of the air heat pumps [2]. Whereas in hot climate conditions, such as in southern Europe, conventional split systems have shown their own disadvantages or limitations. By the other side, growing improvements of geothermal technologies are braked by high initial investments in ground source heat pump systems and by strict regulations [3]. GCHPs are installed especially for profitable and stable thermal conditions in exploiting the ground as thermal source/sink which can reduce significantly the fluctuation of the temperature. Nowadays, two types of ground heat exchangers are widespread: vertical (VGHEs) and horizontal (HGHEs) ground heat exchangers.

VGHEs have higher efficiency but higher purchase and installation cost, whereas HGHEs are inexpensive in term of arrangement and more compliant with environment regulations, but affected by drawbacks for land area requirement and lower efficiency due to less stable thermal condition in shallow ground [4]. Recently, new solutions have led to profitable improvements for overcome these issues, such as baskets, thermal tapes, spiral-tubes, and so on. Among them, the Flat-Panel prototype (FP) developed by University of Ferrara (European patent pending $\mathrm{n}^{\circ}$ EP11177528.4) and depicted in Fig. 1 shows higher performance than all other GHE shapes, as reported in numerical and experimental tests [5-8]. Nevertheless, the payback time of the GHE installation cost remains too long to justify the effort [9]. Therefore, even with an efficient and cheap GHE solution, it could be profitable to exploit on demand an alternative thermal source, such as the air, to reduce the ground energy load and therefore the GHE installation cost, since related to a shorter closed loop. That is the main idea of the hybrid air-ground heat pump system, so called dual-source heat pump (DSHP), which has been designed and installed at University of Ferrara, as goal of the HEGOS project based on the European funds for the regional development (POR-FESR 2014-2020).

A DSHP [10] could be an effective solution to solve the previous issues, joining the performance of air-source and ground-source in a stand-alone system able to switch to the more favourable working conditions. It could grant significant energy saving compared to the reversible air heat exchanger due to better thermal properties of ground-source, its higher stability and its more favourable temperature patterns. By the other side, the GHE size could be considerable reduced according the lower thermal energy exchanged with the ground in comparison with the full GCHP configuration.

This study aims to evaluate the preliminary performance of a real setting of DSHP and its potential benefits over traditional ASHP and GCHP [6]. The analysis is carried out experimentally, as the first step of future studies. 


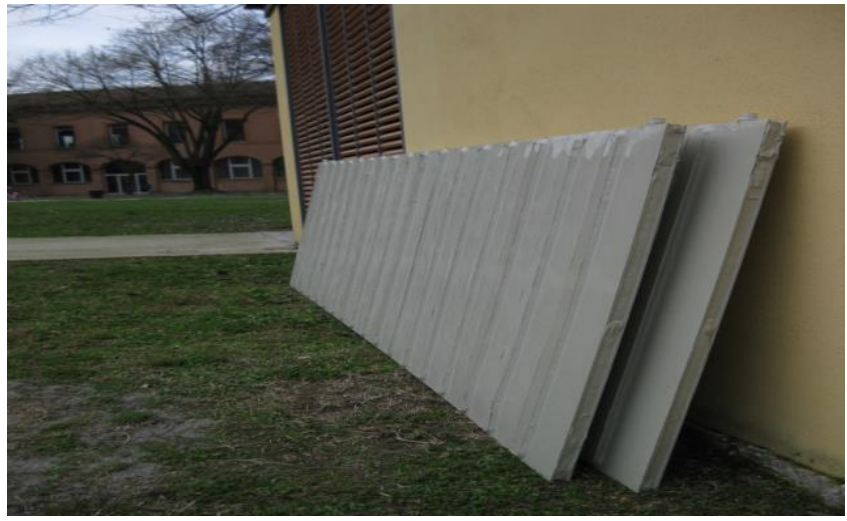

Figure 1. Flat-panel prototype

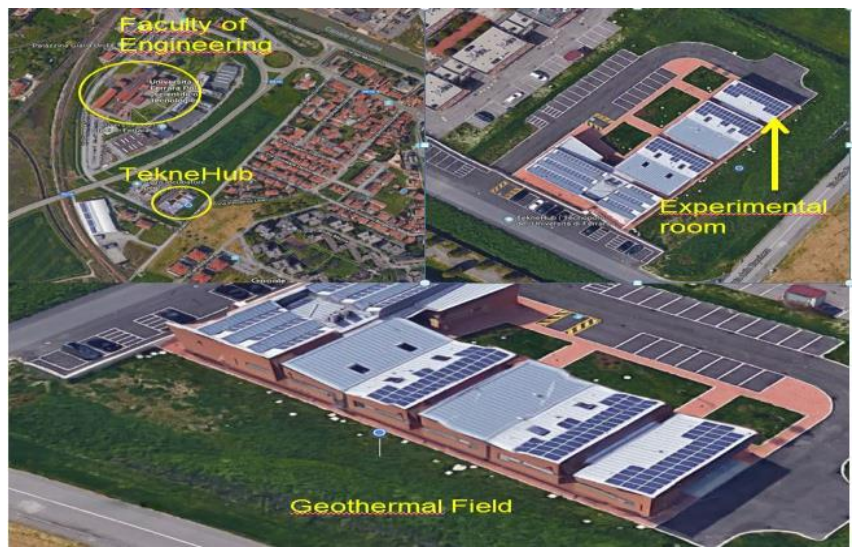

Figure 2. Plant location

\section{TESTING FACILITY}

The facility is operating at the TekneHub (N44.831, E11.599), which is a laboratory of the University of Ferrara belonging to the high technology network of the EmiliaRomagna region (Fig.2). The local climate is usually referred to a continental climate. The winter is harsh and humid, and the temperature often decreases below $0^{\circ} \mathrm{C}$ (2326 heating degree days). The summer is hot and muggy, with a daily temperature often higher than $35^{\circ} \mathrm{C}$.

The facility is composed by a building air-conditioned with the novel DSHP, coupled with a geothermal closed loop installed in the back yard (Fig.2). The DSHP is controlled by a PLC and a comprehensive monitoring system collects data from the HVAC and the ground. Finally, a weather station is devoted to collect the climate parameters as well.

\subsection{The building}

A one-storey small building composed by two rooms has been devoted for testing, since a room has been airconditioned with the novel DSHP (volume of $48 \mathrm{~m} 3$, net floor $16 \mathrm{~m} 2)$. The external walls are made of bricks with a polystyrene thermal insulation layer (calculated U-value of $0.21 \mathrm{~W} / \mathrm{m} 2 \mathrm{~K}$ ). The roof is built with predalles precast roof slabs with $160 \mathrm{~mm}$ of polystyrene thermal insulation layer (Uvalue of $0.20 \mathrm{~W} / \mathrm{m} 2 \mathrm{~K}$ ). The floor consists of an insulated light concrete layer supported by a structural concrete aired slab and a concrete sub-foundation (U-value of $0.24 \mathrm{~W} / \mathrm{m} 2 \mathrm{~K}$ ). Finally, $6.5 \mathrm{~m} 2$ of opening windows are present at the west side (Uvalue of $1.9 \mathrm{~W} / \mathrm{m} 2 \mathrm{~K}$ ).

\subsection{Dual-source heat pump system}

A commercial air-to-air heat pump with rotary inverter compressor and a variable speed indoor unit (2.5 kW, R410a) has been modified to couple a geothermal closed loop via a plate heat exchanger (Fig.3), by modifying the refrigerant piping to bypass the fin and tube air heat exchanger. In the Fig.3, the layout of the built-in copper piping is shown, as redesigned and stretched to allow a new configuration of heat pump system able to divert the working fluid by means of solenoid valves between the two exchangers, according to the signals provided by the PLC. Therefore, DSHP can operate with the air heat exchanger (air mode), the GHEs (ground mode), otherwise mixing previous solutions as well (mix mode). To reduce electric consumption caused by the external fan and avoid frosting, a three phase cut-on is able to turn it off on demand.

The DSHP automation is managed by means of a programmable logic controller (PLC) which allows to switch between the two sources under specific conditions. At the moment, three different operating modes are implemented in the control algorithm:

Automatic: source switching is automatically controlled by the PLC which refers to a parameter set decided by the user (Table 1);

Manual: manual selection of a source mode;

Testing: debug mode for checking the state machine.

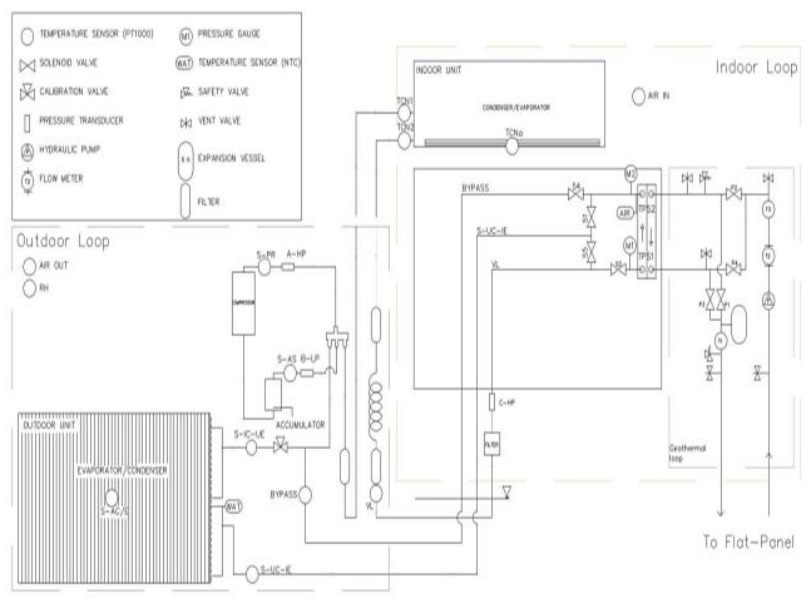

Figure 3. Layout of the dual-source heat pump system

\subsection{Automation system}

The behaviour of the DSHP is managed by means of a programmable logic controller (PLC), which is able to switch between the two thermal sources (air/ground), based on several conditions. The PLC reads continuously data from several sensors (temperature, pressure, ice presence, ...) and drives four solenoid valves to modify the piping according to its control algorithm. It is also equipped with a Modbus unit, used to establish a control net with some devices (energy meters, external temperature and humidity unit, hydraulic pump) and a web server. This latter has been used to implement a web human machine interface (HMI) which allows the remote changing of several set points that affect the PLC decisions (temperature thresholds, timings, hydraulic pump speed, turning on and off the fan etc.). Data are saved in ASCII files and are available for further processing. 
Table 1. Switching control parameters

\begin{tabular}{|c|c|c|c|c|}
\hline Index & Parameters & Winter & Summer & Unit \\
\hline $\mathrm{T}_{\text {dual }}$ & $\begin{array}{l}\text { Air temperature for dual } \\
\text { functionality }\end{array}$ & $<5$ & $>35$ & ${ }^{\circ} \mathrm{C}$ \\
\hline $\mathrm{T}_{\text {water }}$ & $\begin{array}{l}\text { Temperature range for } \\
\text { operating in ground mode }\end{array}$ & -2 & 30 & ${ }^{\circ} \mathrm{C}$ \\
\hline$\Delta \mathrm{T}$ & $\begin{array}{l}\text { Temperature difference } \\
\text { between ground and air } \\
\text { for switching in ground } \\
\text { mode }\end{array}$ & $0: 7$ & $-7: 0$ & ${ }^{\circ} \mathrm{C}$ \\
\hline $\mathrm{t}_{\text {air }}$ & $\begin{array}{l}\text { Shortest time in air mode } \\
\text { before switching }\end{array}$ & 5 & 5 & $\min$ \\
\hline $\mathrm{t}_{\text {water }}$ & $\begin{array}{l}\text { Shortest time in ground } \\
\text { mode before switching }\end{array}$ & 15 & 15 & $\min$ \\
\hline Ice & Defrost control switching & flag & - & - \\
\hline
\end{tabular}

\subsection{Geothermal closed loop}

The geothermal closed loop is made up of three pairs of FPs, each one $2.0 \mathrm{~m}$ long, $1.1 \mathrm{~m}$ high and with an internal cavity of $0.017 \mathrm{~m}$ wide, thus performing a hollow volume of $30 \mathrm{Lt}$. As detailed in Fig.4, the FPs have been edgeways buried in a trench $2.5 \mathrm{~m}$ deep and $0.4 \mathrm{~m}$ wide, backfilled with washed sand. A gravel layer with a dedicated irrigation system has been laid at the top to soak the trench on demand and improve soil thermal performance. For covering, it has been used soil originated from digging. The thermo-physical ground properties are listed in Tab.2, as professionally characterized at the Istanbul Technical University.

The main hydraulic loop depicted in Fig. 5 is composed by 25 meters of insulated DN20 HDPE as main collector, a hydraulic pump, and an expansion vessel; four valve groups allow to partialize the piping, so that every pair of FPs can work alone or in series mode, on demand. Finally, a plate heat exchanger installed in the experimental room performs the heat transfer between brine and refrigerant, in parallel or counter flow according to specific valves state.

To exploit the system up to $-15{ }^{\circ} \mathrm{C}$ and avoid icing of the geothermal working fluid caused by the temperature drop at the plate heat exchanger, $30 \%$ of glycol was added to the working fluid.

Table 2. Thermo-physical soil properties.

\begin{tabular}{cccc}
\hline Material & $\begin{array}{c}\text { Thermal } \\
\text { cond. }(\mathrm{W} / \mathrm{m} \cdot \mathrm{K})\end{array}$ & $\begin{array}{c}\text { Density } \\
\left(\mathrm{Kg} / \mathrm{m}^{3}\right)\end{array}$ & $\begin{array}{c}\text { Specific } \\
\text { heat }(\mathrm{kJ} / \mathrm{Kg} \cdot \mathrm{K})\end{array}$ \\
\hline Sand & 2.75 & 2100 & $0.88-1.1$ \\
Clay & 1.52 & 1860 & $0.92-1.4$ \\
\hline
\end{tabular}

\subsection{Monitoring system}

As summarised in Tab.3, more than 50 sensors split in four different data collecting systems have been installed to control the experimental prototype and to monitor its performance (SGM-Lektra multiplex, Thermo Fisher Scientific data logger, Eliwell PLC, Davis weather station). In ground (Fig.4-5), a first sensor group is installed into boreholes drilled inside and outside the trench, in order to measure the ground temperature at different depths. Then, a thermal heat flux sensor installed $13 \mathrm{~cm}$ away and in front of the FP allows to evaluate the heat flux. A second sensors group monitors temperatures and pressures of the HVAC system in all relevant piping sections. Furtherly, a third group of sensors is deputed to acquire data via PLC in order to evaluate the brine temperature and flow rate.

Moreover, electricity supplied to the DSHP and the circulation pump are monitored by means of two single energy meters. Finally, the ice forming on the external fins of air heat exchanger is detected by means of a leaf-wetness sensor. The ice sensor is able to sense different electrical conductivity of air, water and ice therefore supporting the bypass from air to ground.

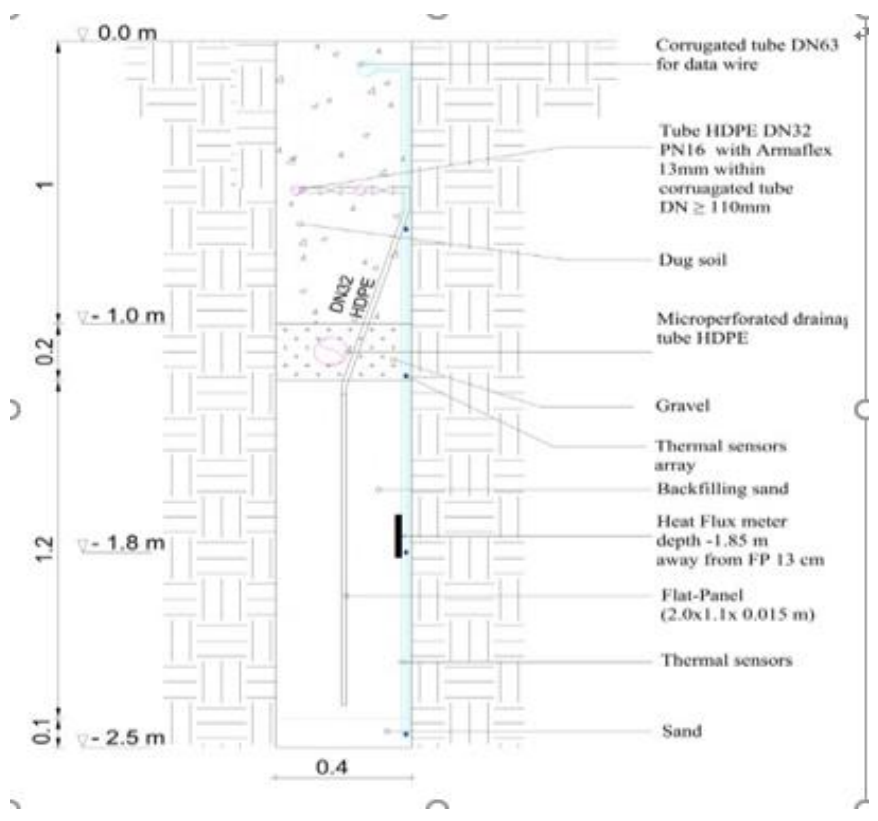

Figure 4. Cross section of Flat-Panel and probes

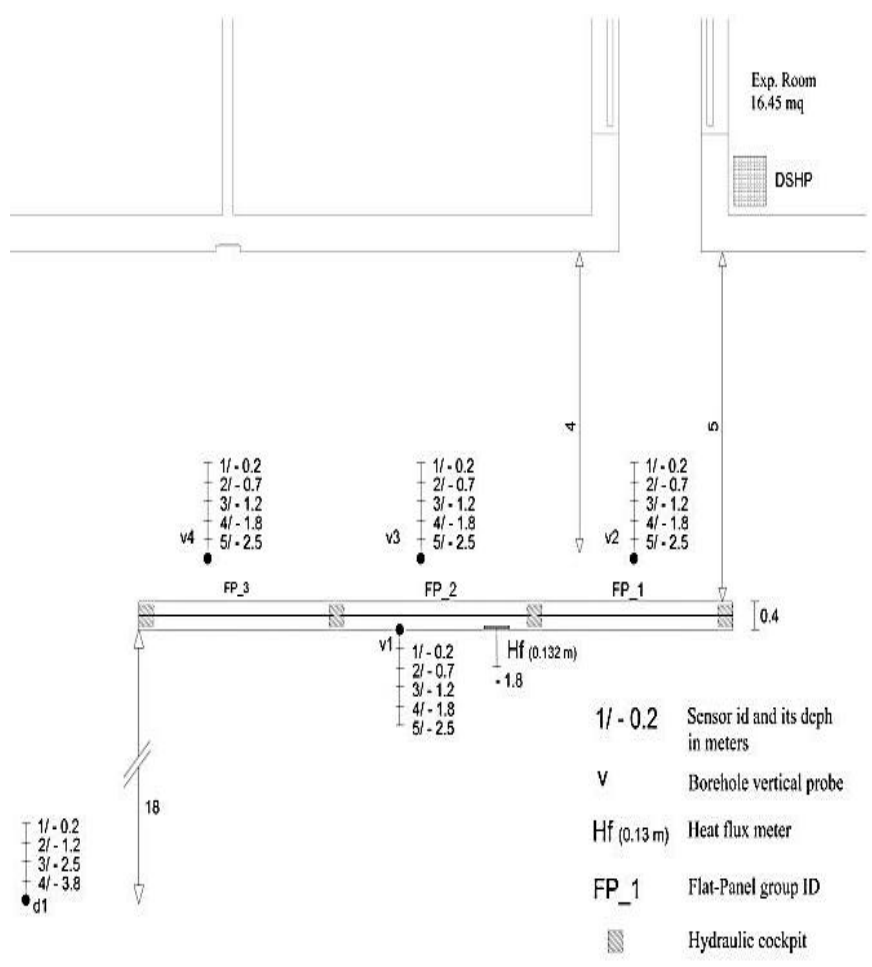

Figure 5. Plan positioning of flat-panel and probes 
Table 3. Sensors array installed

\begin{tabular}{|c|c|c|c|c|c|}
\hline Obj & Parameter & Section & Unit & $\mathbf{N}$ & System \\
\hline \multirow{4}{*}{$\begin{array}{l}\bar{\delta} \\
\dot{n}\end{array}$} & Temperature & Vertical probe group inside trench & ${ }^{\circ} \mathrm{C}$ & 5 & Multiplex \\
\hline & Temperature & Vertical probe group $1 \mathrm{~m}$ far from FP & ${ }^{\circ} \mathrm{C}$ & 15 & Multiplex \\
\hline & Temperature & Undisturbed soil vertical probe group & ${ }^{\circ} \mathrm{C}$ & 4 & Davis \\
\hline & Heat flux & $13 \mathrm{~cm}$ away rom Flat-Panel & $\mathrm{W} / \mathrm{m} 2$ & 1 & DataTaker \\
\hline \multirow{7}{*}{$\begin{array}{l}U \\
\vdots \\
Z\end{array}$} & Temperature & Heat pump piping & ${ }^{\circ} \mathrm{C}$ & 10 & DataTaker \\
\hline & Energy & Heat pump & $\mathrm{kW}$ & 1 & PLC \\
\hline & Ice presence & Fin tube (air heat exchanger) & $\mathrm{S} / \mathrm{m}$ & 1 & PLC \\
\hline & Pressure & Heat pump piping & bar & 3 & PLC \\
\hline & Temperature & Indoor/outdoor & ${ }^{\circ} \mathrm{C}$ & 2 & PLC \\
\hline & Temperature & Output air heat exchanger & ${ }^{\circ} \mathrm{C}$ & 2 & PLC \\
\hline & Relative Humidity & Outdoor & $\%$ & 1 & PLC \\
\hline \multirow{3}{*}{ 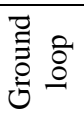 } & Flow rate & Hydraulic pump & $1 / \mathrm{h}$ & 1 & PLC \\
\hline & Energy & Hydraulic pump & $\mathrm{W}$ & 1 & PLC \\
\hline & Temperature & Hydraulic piping & ${ }^{\circ} \mathrm{C}$ & 5 & PLC \\
\hline
\end{tabular}

\section{START UP AND PRELIMINARY RESULTS}

The system has been started in January 2017, but several changes have been performed to improve the low efficiency affecting the ground mode. Indeed, a pressure drop (1 bar) was affecting the system owing to the different piping added to the heat pump. To overcome this issue, the piping cross section was enlarged and the refrigerant loop simplified as well. Moreover, to balance the remaining gas pressure drops between the two different paths (compressor to fin and tube air exchanger, compressor to plate heat exchanger), a calibration valve was also added at the inlet of air heat exchanger. Then, the operation was tested in different working conditions, with different number of FPs, flow rate and periods (Table 4).

Table 4. Operation period monitoring

\begin{tabular}{cccc}
\hline & \multicolumn{2}{c}{$\mathbf{1}^{\text {st }}$ period } & $\mathbf{2}^{\text {st }}$ period \\
\hline & Winter & Summer & Winter \\
\hline Start time & $13 / 2 / 2017$ & $15 / 5 / 2017$ & $10 / 10 / 2017$ \\
End time & $15 / 5 / 2017$ & $10 / 10 /$ & $30 / 4 / 2018$ \\
$\begin{array}{c}\text { Flooded trench } \\
\text { condition }\end{array}$ & $100 \%$ & $30 \%$ & $100 \%$ \\
$\begin{array}{c}\text { Brine flow } \\
\text { rate, }\left(\mathrm{m}^{3} \mathrm{~h}^{-1}\right)\end{array}$ & 0.417 & 0.417 & 0.417 \\
$\begin{array}{c}\text { Indoor air flow } \\
\text { rate, }\left(\mathrm{m}^{3} \mathrm{~h}^{-1}\right) \\
\text { Setpoint, }\end{array}{ }^{\circ} \mathrm{C}$ & 380 & 380 & 380 \\
\hline
\end{tabular}

Particularly, the Fig. 6 shows the different behaviour of the DSHP during the air source mode. The straight lines represent the COP trend under certain conditions related to the outdoor temperature and relative humidity.

When temperature is equal or higher than $3^{\circ} \mathrm{C}$, the COP trend lines have the same slope, while under that threshold it depends by relative humidity value too. The air COP is strongly affected by the defrosting phenomenon which occurs under $3^{\circ} \mathrm{C}$ and a value of relative humidity over $90 \%$.

The following charts (Fig.7-8) show the hourly behaviour of the DSHP during a winter day (19 December 2017). Respectively, the first one shows the air mode operation and the second one the ground mode. High and low pressure of the heat pump operate in the same range, but the gap between the two pressure is wider in air source than the ground mode.
The different behaviour is due to the exchange temperatures of the thermal source, indeed rising low pressure improves compressor performances, extending its useful life.

Moreover, the indoor temperature is lower in the air mode because affected by defrosting cycles which also reduce the overall performance. Therefore, as a consequence, the energy consumption is higher also with more favourable outdoor temperature in comparison with the ground mode that operates at lower outdoor temperature.

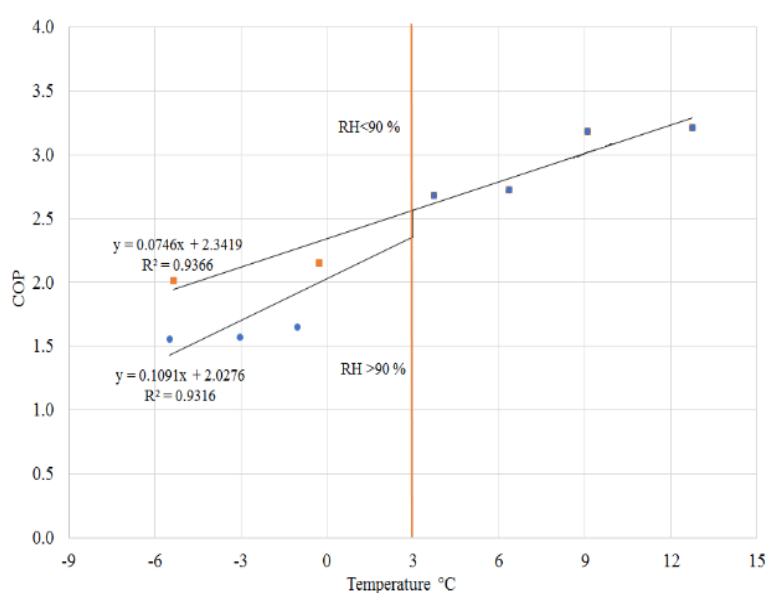

Figure 6. DSHP air mode

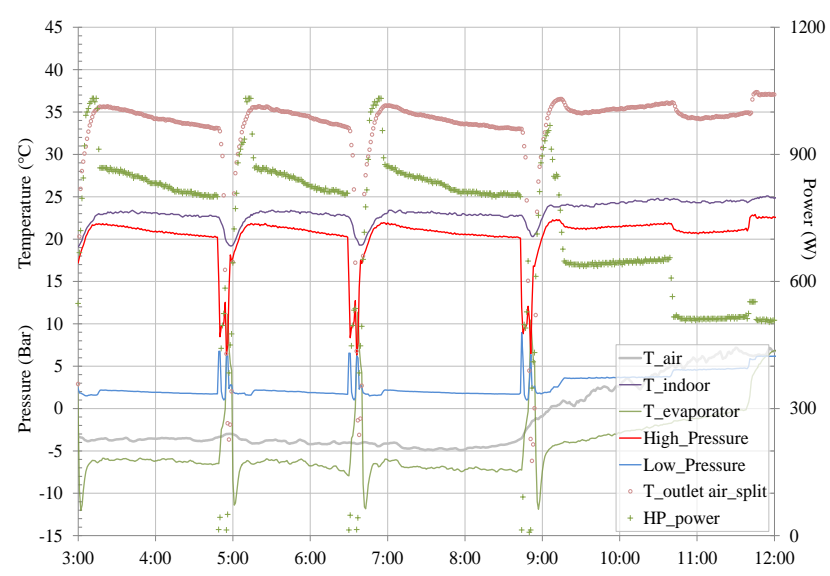

Figure 7. DSHP air mode 


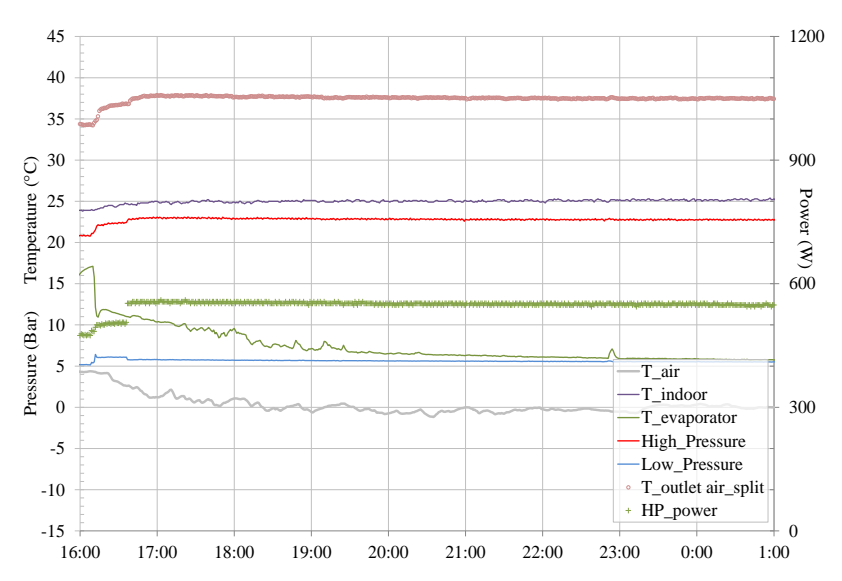

Figure 8. DSHP ground mode

In Fig.9 is depicted the daily behaviour of the DSHP (19 December 2017) with evidence of the better performance in terms of COP of the ground source compared to the air mode. During the monitoring period the outdoor temperature range varies from -5 to $8{ }^{\circ} \mathrm{C}$ and the heat pump is free to select the best source according to the imposed parameters. During the daytime it is possible to see an air COP lower than ground COP; in particular the air COP is the same of the ground source mode at worse night conditions.

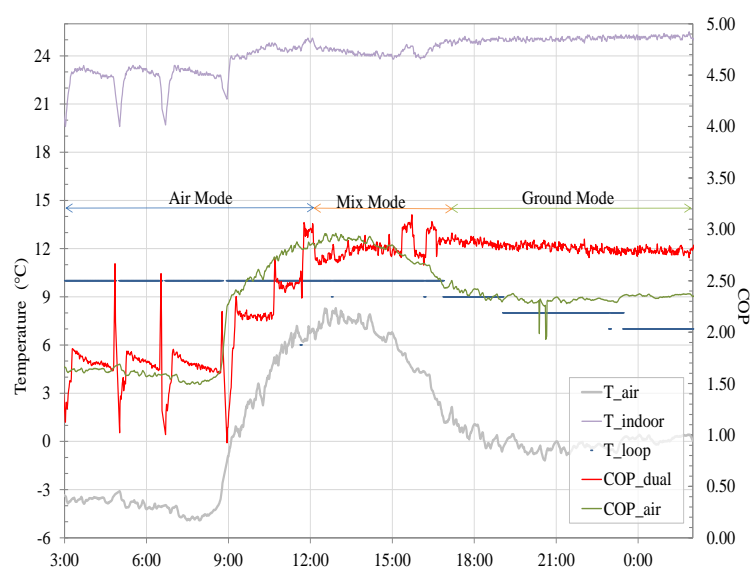

Figure 9. Hourly behaviour of dshp

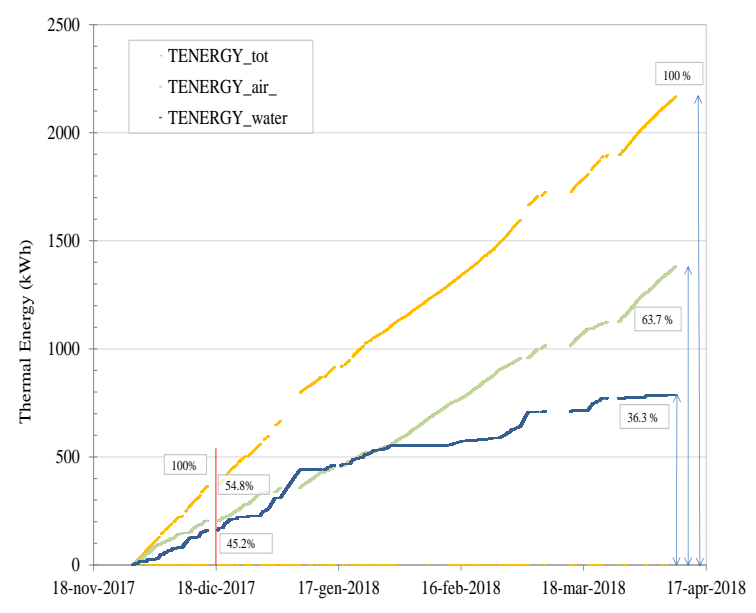

Figure 10. Energy extraction from thermal sources

The gain of the ground source in terms of COP is $10 \%$ higher than air-source mode and drastically higher with lower temperature.
The best working conditions of the heat pump allow the switch and take advantage of the more profitable source temperature of the ground compared to the air.

The best conditions of the ground mode are certainly affected by the exploitation of the source and from other parameters imposed (numbers of Flat-Panels, thermal load and so on). In Fig. 10 the energy exploitation of the two sources is depicted for the overall heating period, respectively equal to $36.3 \%$ for ground and $63.7 \%$ for air. The red line shows the snapshot of the previous day examined where the overall exploitation of the ground-source is less than $50 \%$. Overall, the exploitation of the ground-source plays a crucial role to improve the performance of the heat pump.

In Fig. 11 is showed, the daily behaviour of the DSHP under snowing condition. In addition of the well-known "defrost" of the heat pump, it is notable the icing of trench.

However, compared to the frosting of the heat pump this phenomenon is an advantage for the DSHP because freezes the thermal source temperature on a fixed value of $0^{\circ} \mathrm{C}$ while the outdoor temperature is decreasing below.

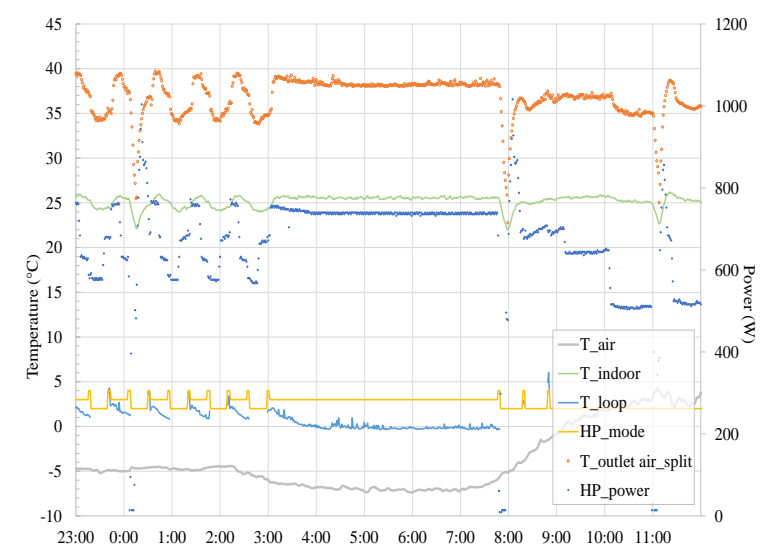

Figure 11. Icing of Trench (27 Feb 2018)

In Fig.12, the yearly ground temperature caused by the FPs is shown in comparison to the unaltered temperature of the soil. These temperatures are referred to the probes sited at different depths respectively at the top (blue line $1.2 \mathrm{~m}$ ), at the bottom (green line $2.5 \mathrm{~m}$ ) and in the middle (orange line $1.8 \mathrm{~m}$ ) of the FPs. Higher peaks occur due to the exploitation of two groups of FP and intensive work of DSHP during the tests in several conditions. Either bottom and top line show a variation regarding unaltered lines about $6-8^{\circ} \mathrm{C}$, and more than 10 degrees using the line corresponding to the FP as a reference. Less than ten days are enough to recover every alteration of the soil temperature, also including the involved domain $1 \mathrm{~m}$ far by the FP. Three FP groups have been fully suitable to meet the overall heating and cooling load needed; nevertheless two groups of FPs are still satisfactory using the imposed working rules on the control system. The number of FP employed has been changed to test different conditions and asses the overall length of the GHEs. Solely one group of two Flat-Panel has been employed to meet the summer period (May to Sept 2017) and winter period (Feb 2018); three group of six FP cover the remaining period.

\section{CONCLUSIONS}

This study has analysed the thermal behaviour of the next generation of heat pumps which will involve more thermal 
sources. The DSHP worked for six months in heating mode, by using ground source operation with an overall heat exchange about $97 \mathrm{kWh}$ for meter of trench. As seen in Fig.10, throughout winter period the use of ground source mode represents the $36 \%$ compared with the most used air source mode $64 \%$. The imposed parameters allowed to modulate the depletion of the ground source, especially using one group of Flat-Panels.

The experimental test shows that coupling shallow ground heat exchanger, (specifically Flat-Panel) with a modified traditional air-to-air heat pump can be a suitable and profitable solution to improve the overall performance. Dual source heat pump allows more favourable working conditions, may decrease the length of the HGHE and therefore can offer an efficient and cost effective solution respect to other widespread expensive solutions. In addition DSHP can also prevent frosting phenomenon on the evaporator by turning on mix mode reducing energy consumption and indoor thermal discomfort due to lowering temperature inside the room. This preliminary tests are promising but further results are to be analysed because the first tests were performed continuously using the DSHP, for testing purpose, by changing every needed boundary condition and often inducing compressor and plate heat exchanger stresses. The next generation DSHP, with short path piping obtained by reducing the distance of the plate heat exchanger from the compressor and removing calibration valve, will be able to ensure higher values of performance.

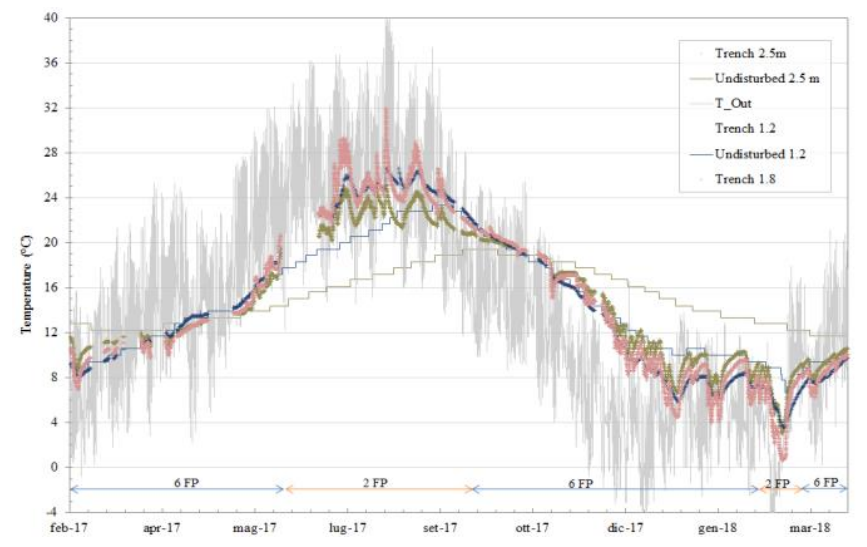

Figure 12. The yearly alteration of the ground temperature

\section{ACKNOWLEDGMENT}

This study has been supported by the European POR-FESR 2014-2020 fund of the region Emilia-Romagna, Italy.
We thank Doç. Dr. A. Alper Aydın of the Istanbul Technical University for his support in assessing the ground thermophysical properties.

\section{REFERENCES}

[1] Gabriel LHT, Chau LW, Chin SH, Hishamuddin MA. (2018). Low-carbon ability of neighbourhood public open space (pos) governance: explanation from socialecological system and new institutional economics. Chemical Engineering Transactions 63: 469-474. https://doi.org/10.3303/CET1863079

[2] Dongellini M, Naldia C, Morini GL. (2015). Annual performances of reversible air source heat pumps for space conditioning. Energy Procedia 78: 1123-1128. https://doi.org/10.1016/j.egypro.2015.11.070

[3] Vocale P, Morini GL, Spiga M. (2014). Influence of outdoor air conditions on the air source heat pumps performance Energy Procedia 45: 653-662. https://doi.org/10.1016/j.egypro.2014.01.070

[4] Fujii H, Yamasaki S, Maehara T, Ishikami T, Chou N. (2013). Numerical simulation and sensitivity study of double-layer slinky-coil horizontal ground heat exchangers. Geothermics 47: 61-68. https://doi.org/10.1016/j.geothermics.2013.02.006

[5] Monteiro FZ, De Siqueira R, Moura FJ, Grillo A. (2018). Study of the thermal decomposition of green coconut fiber in the presence of a nanostructured catalyst. Chemical Engineering Transactions 65: 457-462. https://doi.org/10.3303/CET1865077

[6] Bottarelli M. (2013). A preliminary testing of a flat panel ground heat exchanger. International Journal of LowCarbon Technologies 8(2): 80-87.

[7] Bottarelli M, Li Z, Bortoloni M, Su YH. (2016). Energy performance of a dual air and ground-source heat pump coupled with a Flat-Panel ground heat exchanger. Bulgarian Chemical Communications 48(A): 64-70.

[8] Bortoloni M, Bottarelli M. (2015). On the sizing of a flatpanel ground heat exchanger. International Journal of Energy and Environmental Engineering 6(2): 185-195. D https://doi.org/10.1007/s40095-014-0150-0

[9] Bottarelli M, Gabrielli L. (2016). Financial and economic analysis for ground-coupled heat pump using shallow ground heat exchangers. Sustainable Cities and Society 20: 71-80. DOI: 10.1016/j.scs.2015.09.008

[10] Bottarelli M, Yousif C. (2017). Modelling of shaded and unshaded shallow-ground heat pump system for a residential building block in a mediterranean climate. Journal of Physics: Conference Series 796(1): 012017. https://doi.org/10.1088/1742-6596/796/1/012017 